\title{
Use of Photo-elicitation to evoke and solve Dilemmas that prompt changes Primary School Teachers' visions
}

\author{
Antonio Bautista García-Vera ${ }^{1} \oplus$, Laura Rayón Rumayor ${ }^{2} \oplus$ and Ana María de la Heras Cuenca ${ }^{1} \odot$ \\ ${ }^{1}$ Departamento de Estudios Educativos, Universidad Complutense de Madrid, Spain \\ ${ }^{2}$ Departamento de Ciencias de la Educación, Universidad de Alcalá, Spain
}

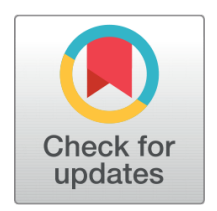

Received 2019-10-11

Revised 2019-10-23

Accepted 2019-11-13

Published 2020-01-15

\section{Corresponding Author}

Antonio Bautista García-Vera,

bautista@edu.ucm.es

Edificio La Almudena, Rector Royo Villanova s/n, Ciudad Universitaria, 28040, Madrid, Spain.

DOI https://doi.org/10.7821/ naer.2020.1.499

Pages: 137-152

Funding: Ministry of Economy and Competitiveness, Spain (Award: EDU2014-57103-R)

Distributed under

Creative Commons CC BY 4.0

Copyright: ( ) The Author(s)

\section{ABSTRACT}

The present article investigates the potentialities of photo-elicitation as a technique in teacher professional development. This study analyses the process of eliciting dilemmas in four primary teachers, whose solution has proved to contribute to the teachers' education. To this end, the effect of different types of external observers' intervention in dilemma generation, participating in sessions developed with a specific photo-elicitation procedure, is explored. The knowledge pursued in order to meet the study objectives concerned inconsistencies between goals and practices and teachers' dilemmas. These inconsistencies and dilemmas are tacit and with multiple possible interpretations, and are therefore not measurable. They consequently require an interpretative research approach using a qualitative method of inquiry based on collective case studies. The results show that the inconsistencies introduced to the teachers, by questioning their teaching practice, are enough but not necessary to pose professional dilemmas. Solving these dilemmas led the teachers to change their conceptual and processual beliefs, as well as their teaching activities.

\section{Keywords PROFESSIONAL TRAINING, TEACHER PARTICIPATION, TEACHER} CUALIFICATION, PHOTO-ELICITATION PROCESSES, TEACHER'VISIONS

\section{INTRODUCTION}

Our study was based on the notion that when teachers are required to solve a dilemma regarding the relationship between their teaching goals and practices, this will lead to changes in their theoretical knowledge and/or practice and thus facilitate their professional development.

Terry (2007) and French-Lee and Dooley (2015), namely when there are at least two possible explanations for a situation that has arisen in a school and the teacher must choose one of them. However, besides exploring the beliefs on which each of the possible explanations for a situation are based, we also examined the dilemmas that arise when teachers must choose between different teaching practices to achieve an educational goal.

With the aim of promoting teachers' professional development, we wished to determine the effect of contradictions between a teacher's beliefs or inconsistencies between teaching

\section{OPEN ACCESS}


goals and practices as regards creating and solving dilemmas.

\subsection{Teachers' visions}

The concept of a teacher's vision refers to an educator's personal stance with regard to the values, ideals or educational goals that students should acquire or attain (Fairbanks et al., 2010; Kennedy, 2006; Lefstein \& Snell, 2011; Vaughn, Parsons, Keyes, Puzio, \& Allen, 2017). Thus, teachers' visions contain two elements; the educational goals of their teaching practice, and how to enact their visions through the work set for students in order to achieve these goals (Parsons, Vaughn, Malloy, \& Pierczynski, 2017). Resolving the contradiction between goals and practice demands and requires a response from teachers (Lindqvist, Weurlander, Wernerson, \& Thornberg, 2017).

Teachers' visions are similar to beliefs (Duffy, 2002) in that they evolve, are shaped by situational experiences and inform teachers' decisions about the dilemmas that arise in their daily practice. However, whereas beliefs pertain to teachers, visions pertain to the students, in terms of their expected academic performance. Said performance may prompt teachers to adapt and/or change their teaching beliefs and theories.

Although studies on beliefs have a longer history, some of the basic issues they have addressed in recent years are similar to those explored in research on teachers' visions. One of these is the question of how pre- and in-service teachers resolve conflicts between their beliefs and between their visions and teaching practice in schools (Nghia, 2017). However, the results to date are inconclusive. For example, Hammerness (2004) found that teachers tended to maintain their vision, even if this was questioned and hindered by the educational institution, whereas Hall (2009) reported that at the end of their initial training, teachers stated that should such conflict arise, they would probably adopt the vision of the school where they were employed and renounce their own visions. Along the same lines, Popp and Goldman (2016) noted the need for teachers to think about their visions and learn how to use them to guide their teaching. In these studies, the question of how contradictions form or emerge between teachers' beliefs or how inconsistencies between the ethical and professional principles that underlie teachers' educational goals and teaching practice has not been addressed in any detail.

Previous arguments concerning teachers' visions have also maintained a conceptual distinction between teachers' contradictions and inconsistencies that could help elucidate the elements and mental processes involved in dilemmas that promote change in teaching practice. Contradictions refer to a teacher's opposing beliefs or to theories antithetical to these; for example, believing that the school is a place for families and tutors to meet while at the same time being convinced that communities and associations of parents and other social agents generate more problems than support for student learning. Meanwhile, inconsistency refers to a lack of agreement between the goals sought for students and the tasks they are set to achieve them, as in the case of trying to promote values of cooperation and solidarity but setting individual and competitive tasks.

Here, we analyse the structure of elements and procedures in intervention and interaction in photo-elicitation sessions that best prompt expression and/or awareness of possible 
inconsistencies and contradictions that generate dilemmas for teachers in their professional practice.

\subsection{Photo-elicitation as a tool for teachers' professional development}

It is necessary to decide how to facilitate the processes generated by questioning, dilemmas and decisions concerning situations in teachers' practice, while also representing or expressing them inform to others.

For this purpose, we selected photo-elicitation. This term was term coined by Collier (1954) in the discipline of anthropology and has subsequently been employed by others such as Glaw, Inder, Kable, and Hazelton (2017), Harper (2002) and Harrison (2002) in reference to data collection that includes photographs in research interviews. In the professional development spaces explored in our study, photo-elicitation offered the possibility of challenging the beliefs perpetuated in teachers' routines and habits by rendering them visible and demonstrating that they underlie many of the actions and decisions taken.

A review of the literature on this method indicates that sessions are most frequently conducted at the request of a teacher who wants to improve his or her practice. The teacher takes the photograph and arranges a session (Birkeland, 2013; Dockett, Einarsdottir, \& Perry, 2017; Legge \& Smith, 2014). The same teacher is also the first to speak, reporting on the content of the photograph, because according to Rose (2016) and Mannay (2017) the most important aspect of a photograph is what its author intends it to communicate. Then, members of the rest of the group participating in the photo-elicitation session verbally analyse and evaluate the teacher's work from their point of view (other colleagues, external observers or students, if they appear in the photograph).

A second way to organise these sessions is for the photograph to be taken by someone other than the teacher who is the subject of professional development (Estepa \& Amador, 2016; Miller, 2016; Richard \& Lahman, 2015; Ruto-Korir \& Beer, 2012; Strickland, Keat, \& Marinak, 2010), to conduct photo-elicitation sessions using photographs taken by students and their parents to inform and ask their respective tutors about homework or to examine interactions between families in relation to the school.

A third approach is aimed at questioning a particular teacher or examining the personal and professional identity of an educator (Kearns, 2012), or depicting contradictions and inconsistencies in a teacher's work (Torre \& Murphy, 2015; Walter, Baller, \& Kuntz, 2012), in order to prompt changes in beliefs or practices. In this case, an external observer takes photographs of something the teacher is doing in his or her professional practice. These photographs are then shared with a group and the observer questions and discusses something depicted in the photographs that appears inconsistent on the part of the teacher evaluated.

Given these three possible options, for the present study we selected the first, in which it is the teacher under analysis to improve his or her practice who records moments of the same and speaks first in the subsequent photo-elicitation sessions. We considered this to be the least confrontational or invasive approach and the one which most respected the teacher's privacy. We also felt that this option, would mitigate any possible hierarchical 
relationships between participants. Thus, any possible contradictions and inconsistencies would be uncovered by our interventions concerning contrasts between several of the photographs presented by the teacher.

\subsection{Research aims}

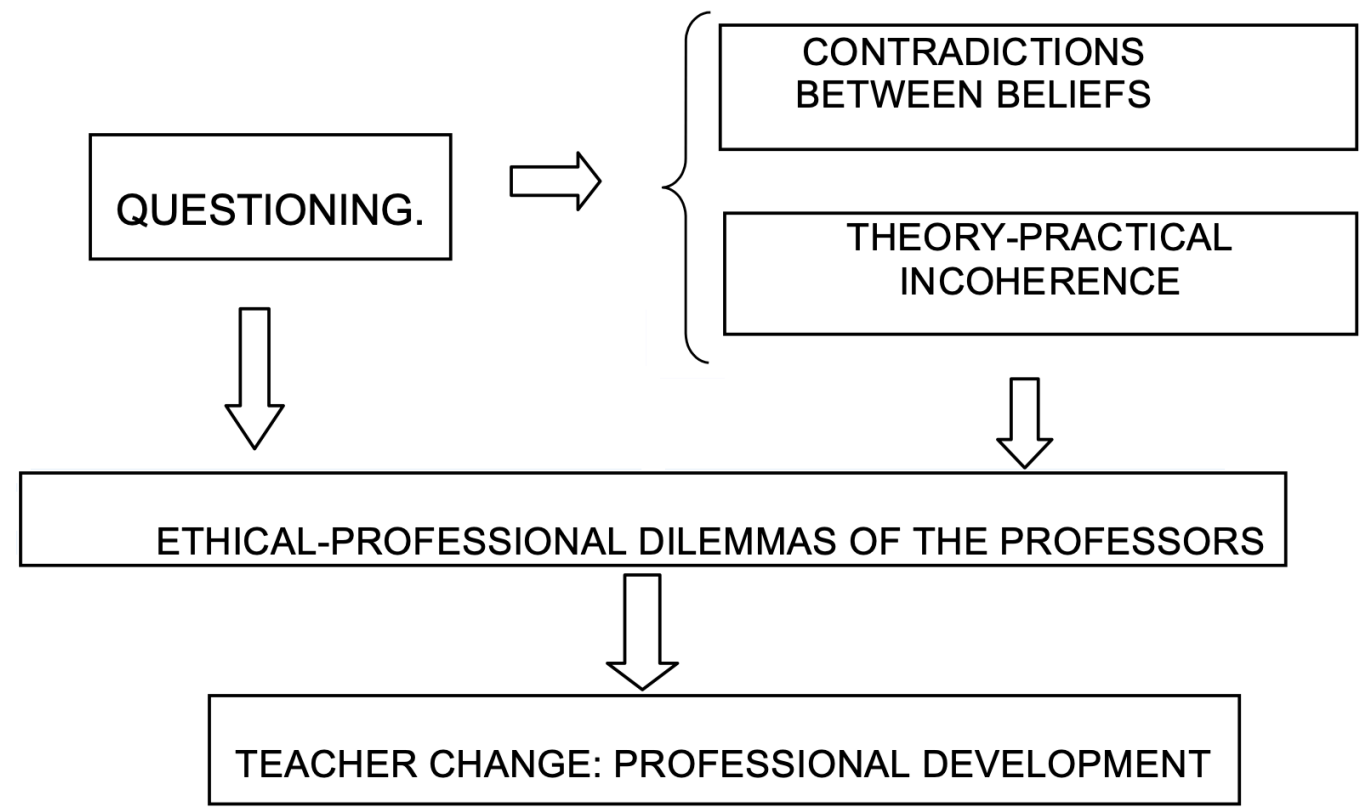

Figure 1 Conceptual itineraries

In light of the elements and itineraries shown in Figure 1, our study objectives were as follows:

- Objective 1: to determine the nature or type of interventions made by external observers participating in photo-elicitation sessions.

- Objective 2: to identify whether dilemmas are generated directly by questions put to the teacher undergoing professional development, or indirectly by the contradictions between beliefs or inconsistencies between goals and practices implicit in the questions.

- Objective 3: to determine the possible changes adopted by teachers as a result of solving the dilemmas identified in objective 2 .

\section{METHOD}

\subsection{Case selection}

To achieve the three study objectives, we collected data on collective case studies (Stake, 1998) of primary school teachers. In order to elicit dilemmas, the following criteria were used to select informants and schools: 
- Schools where more than $80 \%$ of students were from immigrant families, to study classrooms and educational spaces with complex practices and dynamics due to the diversity of the interpretive cultural frameworks involved.

- Cases from at least two schools in different environments (rural and urban), to account for the educational quality of a school provided by the so-called third teacher, i.e. the school environment and school building (Alonso, 2016).

- Teachers with permanent contracts in their schools, to ensure continuity for the duration of the study.

- Teachers with different levels of professional experience.

In line with the above criteria, four teachers were selected from three public schools, two in Madrid and one in Azuqueca de Henares (Guadalajara), located $48 \mathrm{~km}$ from Madrid. Their characteristics are shown in Table 1.

Table 1 Teacherinformants' characteristics

\begin{tabular}{llll} 
Teacher & School Name & Years of Teaching & Managerial Position \\
\hline M & Jaime Vera. Madrid & 7 & No \\
C & Concepción Arenal. Madrid & 32 & Yes, 2007-2015 \\
P & La Paloma. Azuqueca Henares (Guadalajara) & 25 & No \\
S & La Paloma. Azuqueca Henares (Guadalajara) & 15 & Yes, 2010-2018 \\
\hline
\end{tabular}

\subsection{Data collection}

To obtain data on teachers' dilemmas, contradictions and inconsistencies, the four teachers were given a camera and, consequently, to use the language of photography as a means to represent and visually communicate these mental processes (Banks \& Zeitlyn, 2015; Barthes, 1989). Another important aspect of photography in data collection within situations of photo-elicitation, is that it mitigates any possible hierarchical power relations that may exist between researcher and informan (Clark \& Morriss, 2017; Collier, 1954; Grimmet, 2018; Harper, 1987; Kearns, 2012; Walls \& Holquist, 2019). It was for these reasons, that we employed this technique to collect data, asking the four teacher informants to take photographs that would form the basis of their respective sessions. They were given the following information:

- About the study aims: to determine the mental processes that give rise to teachers' dilemmas and identify how these are solved.

- On the content of the photographs to take: teaching situations in class and in the school that they considered normal, extraordinary or emerging and unanticipated.

- On the number of photographs and frequency of sessions: at least one photoelicitation session every 45 days, to analyse, discuss and ask about two or three situations, each depicted in a photograph. 
- On the participants: besides the teacher and one or two researchers, those appearing in the photograph would also be invited to participate. The students' parents gave their consent for use of all images and audio recordings in which their children appeared, having been assured that these would be used solely for research purposes.

- On the photo-elicitation session procedure: in line with the arguments presented in the previous sections, the four teachers comprising the case studies were responsible for taking pictures. When a teacher had taken several, she contacted the researchers to arrange a session. In each photograph, and as a focus group, she would speak first, describing it and/or explaining the content, before the other participants contributed, generating relevant dialogue. Audio recordings were made of the sessions. The total number of sessions and photographs are shown inTable 2.

\begin{tabular}{|c|c|c|c|}
\hline Teacher & Years & No. Sessions & No. Photographs \\
\hline M & $2016-2017$ & 6 & 24 \\
\hline $\mathrm{C}$ & $2016-2017$ & 6 & 19 \\
\hline $\mathrm{P}$ & $2016-2017$ & 5 & 23 \\
\hline S & $2016-2017$ & 5 & 18 \\
\hline Total & & 22 & 84 \\
\hline
\end{tabular}

\subsection{Data analysis}

\subsubsection{Phase 1. Initial analysis}

The audio recordings of the photo-elicitation sessions were transcribed, and the interventions of the teacher and the external researcher-observers participating in each session were analysed in order to accomplish the first study objective. This first analysis was carried out with the administrative assistance (Gibbs, 2007) of NVivo10 software; specifically its search tool.

Using the information thus obtained, we then analysed the intentionality of each type of intervention. It was also interesting for discussion of the data to determine the reasons or motivations that prompted the teacher to take the photograph and the nature of the information provided: physical-denotative, conceptual-connotative and affective.

\subsubsection{Phase 2. Analysis to answer the objetives}

\section{- Subphase 2.1}

To respond to the first objective,we analysed and grouped the external researcher-observers' interventions according to their purpose, considering two types: requesting more information or asking about the information provided. Since it was not possible to use NVivo12 software to analyse and group the data, this was performed manually, employing the conceptdriven coding approach (Barbour \& Morgan, 2017; Gibbs, 2007; Rapley, 2014; Schreier, 
2014). Since observer interventions other than the two mentioned above did not have a prior conceptual framework, these were analysed and grouped manually using the datadriven coding approach. Figure 2 shows the table employed to facilitate identification and grouping of the information indicated above, especially that of the external observers. For example, sections 1 and 2 of the table were designed to group data relevant to the first objective, i.e. to identify and group the different types of external observer intervention.

\begin{tabular}{|c|c|}
\hline SCHOOL/YEAR/SESSION/DATE & \\
\hline PHOTOGRAPH NO. / TEACHER & \\
\hline 1.0. TEACHER'S INTERVENTION & \\
\hline $\begin{array}{l}\text { DESCRIPTION OF PEOPLE AND ACTION OR } \\
\text { SITUATIONS }\end{array}$ & \\
\hline $\begin{array}{l}\text { NATURE OF THE INFORMATION ELICITED: } \\
\text { PHYSICAL-DENOTATIVE, CONCEPTUAL- } \\
\text { CONNOTATIVE, AFFECTIVE }\end{array}$ & \\
\hline $\begin{array}{l}\text { 2.0. EXTERNAL OBSERVER-PARTICIPANT } \\
\text { INTERVENTIONS }\end{array}$ & \\
\hline REQUESTING MORE INFORMATION & \\
\hline ASKING ABOUT INFORMATION & \\
\hline QUESTIONING THE TEACHER'S WORK & \\
\hline OTHERS & \\
\hline 3.0. EMERGENCE OF DILEMMAS & \\
\hline CONTRADICTIONS BETWEEN BELIEFS & \\
\hline INCONSISTENCIES BETWEEN GOALS- & \\
\hline PRACTICES & \\
\hline OTHERS & \\
\hline 4.0. TEACHERS' CHANGES & \\
\hline VARIOUS & \\
\hline
\end{tabular}

Figure 2 Template used to record types of intervention inphoto-elicitation sessions

In order to identify the content of each type of external observer intervention identified a priori, in one of the inter-school meetings, it was agreed that REQUESTING could be defined as seeking more information than the teacher had provided. ASKING, on the other hand, was defined as inquiring into the motives or reasons that led to the teacher to take a decision or make an assessment. Lastly, we considered another possible emerging form of participation, which we termed QUESTIONING. This referred to external observer interventions aimed at evidencing contradictions and inconsistencies in the teacher's practice in class or the school. These would typically employ a WHY..., IF... structure. For example: why do you set your students simple, single answer tasks, if your aim is to encourage their creativity?

\section{- Subphase 2.2}


To accomplish objective 2, it was necessary to determine the effect of these types of external observer interventions on the four teachers undergoing professional development in terms of change and professional improvement. The mental processes targeted by this objective were studied to identify when dilemmas emerged for the teachers, whether directly, as a result of the content of the questions posed, or indirectly, as the teachers' response to any possible contradictions or inconsistencies brought to their attention. This process was carried out manually using an approach similar to that employed with the data for objective 1 , adding a third block to the table inFigure 2 concerning the emergence of dilemmas, contradictions and inconsistencies (Table 2). We used the same coding procedures as for the previous objective: concept-driven coding to confirm or not prior categories of contradictions and inconsistencies, and data-driven coding to identify possible emerging categories.

To standardise the procedure and the referents used to detect beliefs, and subsequently analyse the possible contradictions between them, we held a practical, inter-school session with the teachers to read the transcribed interventions from one session. Teacher C's second session was selected at random. Participants selected this teacher's assertions regarding an episode in the class or school that they considered to be true, despite the absence of clear evidence or theoretical postulates that would distinguish them from any that were false. Among others, the following four were identified:

1. "When there is aggression and we intervene rather than turning a blind eye to these behaviours, the students realise that they are safe in school".

2. "I think that the children maintain conflicts about absurd things over time, permanently".

For example, 1 and 2 are somewhat contradictory because the former states that teachers systematically intervene when aggression arises between students, so that they feel and are safe; however, the latter states that the children maintain long-lasting conflicts.

To identify the teachers' emerging or elicited DILEMMAS, it was agreed at the interschool meetings held for this purpose that the mental processes concerning a teacher's uncertainties would be evidenced verbally in doubts or self-questioning with regard to tasks performed or how to proceed or choose from among several ways of acting. For example: "What should I do with this girl?", "Am I doing what I should?" or "How do you question the professionalism of a teacher who relies entirely on the textbook?"

\section{- Subphase 2.3}

As regards objective 3, the necessary data were associated with teachers' changes. In this case, no prior conceptual categories were established. Therefore, the analysis was conducted by adding a fourth block to the template in Figure 2, with information on changes observed or evidenced by the teachers. This information was then analysed employing the manual data-driven coding procedure described above. 


\section{RESULTS}

An analysis of the data described in the preceding section yielded the results shown in Annex 1 (Supplementary Material) y Table 3. The first of these, Annex 1 (Supplementary Material) details all the photo-elicitation sessions arranged by the four teachers in which the external observers requested more information, asked about the information provided or questioned the work of the teacher participating in the session. It also shows each teacher's dilemmas and changes. Thus, Annex 1 (Supplementary Material) contains information on 31 situations discussed at the 22 sessions held, each identified by the photograph taken by the teacher that prompted the session.

In the column REQUESTING more information from the teacher, only a representative sample is shown of the total number of 386 requests for additional information, due to space limitations. The data given in the columns ASKING, QUESTIONING and DILEMMAS represent the total generated in the photo-elicitation sessions held.

Annex 1 (Supplementary Material) also gives the changes prompted in the four teachers. Three types of data-driven categories emerged from this analysis, two of which concerned changes in beliefs while the third concerned changes in teaching practice. The first two were classified as changes in conceptual and procedural beliefs. The first of these grouped statements about a change in the essential meaning or value of a specific element in teaching, For example, "The school should be seen as consisting not solely of groups of students, but also of groups of parents" and "Tests are a learning activity, and transform assessment into an educational process". Meanwhile, changes in procedural beliefs grouped statements about a new relationship between the meaning of one teaching element and another, or a revised assessment of its benefits for student development. This has a more relative value than that of conceptual beliefs. For example, those identified included the following: "Arranging the desks in a circle so that the children can look each other in the eye doesn't distract them", or "Some teachers' resistance to change is due to their lack of training".

Changes in teaching practice were identified by teachers' proposals for solving a conflict or dilemma that emerged in the photo-elicitation sessions. For example: "Ask each of the three students involved in an aggression to write a letter on how to make amends for the harm caused" or "Give training sessions to teachers who have students with learning difficulties".

In addition to the total number of interventions and the content of each category presented in Annex 1, Table 3 shows all the times that each of the teachers and the corresponding researcher spoke. This table enabled us to determine the relative importance or value of each of the categories from their total percentage.

Table 3 shows that of the external observers' 1561 interventions, 368 (23.5\%) were to request more information, $19(1.2 \%)$ to ask about the information provided and none involved questioning or evidencing contradictions or inconsistencies. The remaining interventions consisted of agreeing with the teacher's discourse, for example by saying "yes", or "very good" or "I see". The former interventions indicated 0 instances of contradictions and inconsistencies, 14 dilemmas and 56 changes, of which 29 concerned conceptual and procedural beliefs and 27 teaching practices. 
Table 3 Resultados totales porcategorías y maestra

Total results by category and teacher

Teacher interventions

Observer interventions

Requesting information (observers)

Asking about information (observers)

Questioning or evidencing contradictions and inconsistencies

Teachers' dilemmas / conflicts

Change in conceptual beliefs

Change in procedural beliefs

Changes in teachers' teaching practice

\begin{tabular}{lllll} 
M & C & P & S & Totals \\
\hline 512 & 541 & 498 & 234 & 1785 \\
445 & 463 & 421 & 232 & 1561 \\
128 & 98 & 101 & 41 & 368 \\
5 & 1 & 7 & 5 & 19 \\
0 & 0 & 0 & 0 & 0 \\
& & & & \\
2 & 1 & 4 & 7 & 14 \\
5 & 4 & 5 & 0 & 14 \\
3 & 3 & 7 & 2 & 15 \\
3 & 7 & 7 & 10 & 27
\end{tabular}

To facilitate an analysis of the nature of these 14 dilemmas, they are grouped in Table 4 according to when they emerged, whether before or during the photo-elicitation session, and their relationship with the content of the photograph that prompted it.

Table 4 Time when dilemmas emerged and relationship with the photograph taken

\begin{tabular}{lllll} 
Dilemmas & & $\begin{array}{l}\text { Direct Relationship with } \\
\text { Photograph }\end{array}$ & $\begin{array}{l}\text { Indirect Relationship with } \\
\text { Photograph }\end{array}$ & Total \\
\hline $\begin{array}{l}\text { Emergence Prior } \\
\text { elicitation Session }\end{array}$ & to Photo- & 9 & 1 & 10 \\
& $\begin{array}{l}\text { P9, P10, S2, S3, S5, S6, S8, } \\
\text { S9 y S11 }\end{array}$ & C2 & \\
$\begin{array}{l}\text { Emergence during } \\
\text { elicitation Session }\end{array}$ & Photo- & 4 & 0 & 4 \\
Total & M3, M5, P7 y P13 & & 14 \\
\hline
\end{tabular}

As can be seen in Table 4, 13 of the 14 dilemmas were directly related to the photograph, which either evidenced them before the session, when teachers experienced them in their teaching work, or emerged during the session, prompted by the researchers' questions.

\section{DISCUSSION OF THE RESULTS}

\subsection{First discussion}

With regard to the first study objective, one of the most striking results obtained was the absence of questioning on the part of the external observers. This might have an attitudinal explanation related to the prudence and courtesy shown by the external observers, since at no time did they seek to place the teachers in an uncomfortable or difficult situation as regards their teaching practice. Another explanation might be of a procedural nature, referring to the researcher-observers' difficulty in analysing and identifying contradictory situations or beliefs and possible inconsistencies between the teachers' goals and practices. This difficulty arose because each photo-elicitation session was based on photographs taken since the previous session and the observers had not therefore seen them 
before. Consequently, the procedure employed gave the observers neither the space nor the time to analyse and contrast each set of photographs or compare them with those from previous sessions in order to identify possible contradictions between the meanings that the teachers attributed to them and subsequently ask about them in the sessions.

It should be noted that although no contradictions or inconsistencies were identified, this does not imply that they did not exist or occur, but rather that they were not depicted or made explicit and therefore could not be analysed. This suggests the need to include a comparison of all the photographs - those from previous sessions and those for the following session - in the photo-elicitation session procedure, as well as time for analysis of contradictions between the teacher's beliefs or inconsistencies in teaching goals and practices.

\subsection{Second discussion}

Despite the observers' lack of questioning, with regard to the second study objective the photo-elicitation sessions identified 14 dilemmas for the teachers, prompted by the other two types or categories of intervention; in other words, by the 365 instances of requesting additional information, and above all, by the 18 instances of asking about information. With regard to the latter, Annex 1 (Supplementary Material) shows that two of the questions addressed to teacher M prompted a professional dilemma: "I'll have to think about it. I really don't know how, I don't even know if this is the best way". This was not the result of having evidenced a contradiction or inconsistency, but of two connected questions that served to indicate an inconsistency in the teacher's decisions. Specifically, she was asked "Do you think it's a good idea to keep the boy in during break? Don't you think that there might be another solution that's less upsetting? Individually, these questions also served to elicit dilemmas that the teachers were already aware of. Such was the case of C (see C2/C in Annex 1 (Supplementary Material), who, when asked "Why do you spend almost all of the week on instructional tasks in maths, language, etc.?", responded "Yes, this is one of my dilemmas. On the one hand, I know how important it is to facilitate student development so that they are good people, but on the other, these are the subjects included in the official curriculum, and will be externally assessed". In this case, the question and the dilemma were not directly related to the photograph taken by $\mathrm{C}$.

In contrast, the rest of the dilemmas identified in sessions with teachers $\mathrm{S}$ and $\mathrm{P}$ did not emerge from the observers' questions but were the reason that had prompted the teachers to take the photographs, which depicted conflicts and dilemmas in their practice that they did not yet know how to tackle. In these cases, the meanings - and sometimes the emotionsinvolved in the dilemma generated in their work formed the subject or content of the photograph taken to represent it visually. One of the situations that illustrate this is that of $\mathrm{P}$ (P9/P in Table 3): when the observer asked "You say you have the tests on your desk and it doesn't matter. Why doesn't it matter?" P replied "It's one of my dilemmas. What's the good of setting students a test, finding that some have done it well and some haven't, giving them a mark and moving on? What's the good of saying you got a 5, and moving on?". The dilemma of teacher S (S8/S in Annex 1, Supplementary Material) was similar: "What can 
you do about teachers who do not comply with the colleague support plan?”. We found that teacher $\mathrm{S}$ was already aware of this dilemma before the session, and that this had prompted her to take a photograph of a desk and chair in the corridor to represent teachers who did not provide adequate support. She had taken the photograph to provide a visual representation of the dilemma for subsequent analysis and discussion in the next photo-elicitation session.

Regarding the proportion of types of observer intervention, the same trend was observed in all four cases. Thus, $75.3 \%$ of their interventions consisted of agreeing with the teachers' statements. This reflects the priority the researchers gave to cognition or inquiry in the photo-elicitation sessions rather than to the teachers' professional development, which accounted for $23.5 \%$ of interventions aimed at requesting additional information, $1.2 \%$ of questions about the motivations or intentions behind some of the teachers' decisions or actions and $0 \%$ of questioning about possible contradictions between beliefs or inconsistencies between teaching goals and practices. However, our results show that requesting more information and above all, asking about the reasons behind the teachers' practices elicited dilemmas and changes. Thus, it was not absolutely necessary to evidence contradictions or inconsistencies in teaching practice through questioning in order to prompt dilemmas. A double question asked with surprise had a notable effect on eliciting dilemmas and proposals for change in the teacher subject to this kind of questioning.

A comparison of the teachers' dilemmas indicated a marked quantitative difference between the 7 dilemmas expressed by teacher $S$ and the 2, 1 and 4 expressed by $\mathrm{M}, \mathrm{C}$ and $\mathrm{P}$, respectively. There was also a qualitative difference whereby all of S's dilemmas concerned teaching staff whereas all of the others' dilemmas concerned the students. Both differences can be explained by S's dual role as teacher and head teacher; her professional conflicts were primarily generated by the attitudes and practices of the school's teaching staff.

As regards the moment when the dilemmas emerged and the function of the photographs in this process, Table 4 , shows that the teachers were already aware of 9 of the 14 dilemmas prior to the photo-elicitation sessions. Nevertheless, these processes of reflection and dialogue proved valuable to elucidate the dilemma using the photographs, analyse it and subsequently resolve it by changing conceptual and procedural beliefs and teaching practices. These results confirm the value of the photographs, although in one of the cases $(\mathrm{C} 2 / \mathrm{C})$, the dilemma was elicited indirectly rather than directly by the photograph analysed, in the process it triggered.

In connection with this, we found that although the mean duration of each photoelicitation session was between 60 and 70 minutes, there was a marked quantitative difference between teachers' interventions whereby $S$ made half the number of those made by M, C and P. This was because each of S's interventions was longer, as she employed a more reflective expository style when discussing the impact of some teachers' lack of professional commitment with their work at the school. 


\subsection{Third discussion}

We also observed a relationship between the content of the dilemmas and the changes effected by the teachers (study objective 3 ). With regard to the relationship between these changes and years of experience and length of service in the school, the two teachers with management experience presented fewer changes in beliefs, while more changes in teaching practice were observed in the teachers with more experience than $M$, explained by the latter's smaller repertoire of practices. We also observed that the 19 questions asked by the observers did not always stimulate change, but sometimes a strengthening of beliefs or practices. Such was the case of M, who, when asked why she had taken her students into the corridor to draw and write with their books resting on the floor (M4/M in Annex 1), replied "I think that a change does them good. It was a nice day, shared with other classrooms".

Lastly, as regards the nature of the dilemmas and the practices changed or adopted by the teachers, we found that these were best explained by the school or institutional context rather than by the socio-cultural context, because of the 14 dilemmas, 9 had emerged prior to the photo-elicitation sessions, during the teachers' experience of working in the institution, and only one (P10/P) was of a social-affective nature. Of the practices changed or adopted by the teachers to resolve the conflict implicit in each dilemma, 3 of the 27 involved $\mathrm{P}$ and $\mathrm{S}$ and concerned the social community: one (P10/P) was related to peer acceptance of a boy, while the other two (S1/S and S2/S) were aimed at encouraging families to participate in school affairs. Both teachers worked at the school located in a rural environment. The other 24 changes were related to student or institutional issues.

\section{CONCLUSIONS}

With regard to the first objective, the observers made three types of intervention. Besides expressing agreement with the teachers' discourse, the two types of most interest in the present study were those aimed at obtaining more information from the teachers or determining the reasons for some of their actions or decisions. It was this latter type that elicited dilemmas in the teachers. The observers did not question the teachers' practices, but in one case, a double question triggered a dilemma for the teacher and a new proposal for teaching practice.Regarding the second objective, we found that two thirds of the dilemmas raised in photo-elicitation sessions had been depicted in photographs of their practice in class and in the school by the teachers prior to the sessions. We therefore conclude that questioning was sufficient but not necessary to prompt dilemmas for the teachers. Furthermore, these dilemmas can be elicited directly by observers' questions, without the need to draw attention to contradictions and inconsistencies in teaching practice. One unforeseen conclusion is that the teachers were able to express their professional dilemmas, and depict them in photographs, prior to the photo-elicitation sessions. In sum, we conclude that the processes involved in photo-elicitation play a valuable role in teachers' professional development, enabling teachers to elucidate and represent their conflicts and reach solutions by changing conceptual or procedural beliefs or changing or adopting teaching practices. Photo-elicitation sessions will prompt more dilemmas for teachers if observers ques- 
tion their practice by indicating contradictions between beliefs or inconsistencies between their teaching goals and practices. Hence, we recommend using the third type of photoelicitation procedure described in the review of the state of the question, where the external observer takes the photographs that form the basis of each session with a teacher, comparing these with photographs used in previous sessions in order to detect possible contradictions and inconsistencies and discuss them in the next session.

\section{ACKNOWLEDGEMENTS}

Funded by: Ministry of Economy and Competitiveness, Spain

Funder Identifier: http://dx.doi.org/10.13039/501100003329

Award: EDU2014-57103-R

\section{ADDITIONAL INFORMATION AND DECLARATION}

- Data set: Bautista García-Vera, A., Rayón Rumayor, L., \& de las Heras Cuenca, A. M. (2019). Use of photo-elicitation to evoke and solve dilemmas that prompt changes primary school teachers' visions [Data set]. Zenodo. http://doi.org/10.5281/zenodo. 3592090

\section{REFERENCES}

Alonso, A. (2016). Maestra, aquí no me gusta estar. Libro de actas del IV Congreso Internacional de Investigación e Innovación en Educación Infantil y Primaria (pp. 119-127). Murcia: Universidad de Murcia. Retrieved from http://congresos.um.es/content/coni3p/9788460881896.pdf

Banks, M., \& Zeitlyn, D. (2015). Visual Methods in Social Research. London: SAGE.

Barbour, R., \& Morgan, D. L. (2017). A new era in focus groups: Challenges, innovations and practice. London: Palgrave MacMillan. https://doi.org/10.1057/978-1-137-58614-8

Barthes, R. (1989). La cámara lúcida. Barcelona: Paidós.

Birkeland, A. (2013). Research dilemmas associated with photo elicitation in comparative early childhood education research. Research in Comparative and International Education, 8(4), 455-467. https://doi.org/10.2304/rcie.2013.8.4.455

Clark, A., \& Morriss, L. (2017). The use of visual methodologies in social work research over the last decade: A narrative review and some questions for the future. Qualitative Social Work, 16(1), 29-43. https://doi.org/10.1177/1473325015601205

Collier, J. (1954). Photography in Anthropology: A Report on Two Experiments. American Anthropologist, 59(5), 843-859. https://doi.org/10.1525/aa.1957.59.5.02a00100

Dockett, S., Einarsdottir, J., \& Perry, B. (2017). Photo elicitation: Reflecting on multiple sites of meaning. International Journal of Early Years Education, 25(3), 225-240. https://doi.org/ 10.1080/09669760.2017.1329713

Duffy, G. G. (2002). Visioning and the development of outstanding teachers. Reading Research and Instruction, 41(4), 331-344. https://doi.org/10.1080/19388070209558375

Estepa, A., \& Amador, J. (2016). Wearable cameras as a tool to capture preservice teachers'marked and recorded noticing. Journal of Technology and Teacher Education, 24(3), 281-307. 
Fairbanks, C. M., Duffy, G. G., Faircloth, B. S., He, Y., Levin, B. B., Rohr, J., \& Stein, C. (2010). Beyond knowledge: Exploring why some teachers are more thoughtfully adaptive than others. Journal of Teacher Education, 61, 161-171. https://doi.org/10.1177/0022487109347874

French-Lee, S., \& Dooley, C. M. (2015). An exploratory qualitative study of ethical beliefs among early childhood teachers. Early Childhood Education Journal, 43(5), 377-384. https://doi.org/ 10.1007/s10643-014-0659-0

Gibbs, G. R. (2007). Analyzing qualitative data. London: SAGE. https://doi.org/10.4135/ 9781849208574

Glaw, X., Inder, K., Kable, A., \& Hazelton, M. (2017). Visual Methodologies in Qualitative Research: Autophotography and Photo Elicitation Applied to Mental Health Research. International Journal of Qualitative Methods, 16(1), 1-8. https://doi.org/10.1177/1609406917748215

Grimmet, K. (2018). Using photo-elicitation to break the silence. In M. L. Boucher (Ed.), Participant Empowerment Through Photo-elicitation in Ethnographic Education Research (pp. 71-92). San Marcos, TX: Springer. https://doi.org/10.1007/978-3-319-64413-4_4

Hall, L. (2009). A necessary part of good teaching": Using book clubs to develop preservice teachers' visions of self. Literacy Research and Instruction, 48(4), 298-317. https://doi.org/10.1080/ 19388070802433206

Hammerness, K. (2004). Teaching with vision: How one teacher negotiates the tension between high ideals and standardized testing. Teacher Education Quarterly, 31(4), 33-43.

Harper, D. (1987). The visual ethnographic narrative. Visual Anthropology, 1(1), 1-19. https:// doi.org/10.1080/08949468.1987.9966457

Harper, D. (2002). Talking about pictures: a case for photo elicitation. Visual Studies, 17(1), 13-26. https://doi.org/10.1080/14725860220137345

Harrison, B. (2002). Photographic visions and narrative inquiry. Narrative Inquiry, 12(1), 87-111. https://doi.org/10.1075/ni.12.1.14har

Kearns, S. (2012). Seeking researcher identity through the co-construction and representation of young people's narratives of identity. Educational Action Research, 20(1), 23-40. https://doi .org/10.1080/09650792.2012.647637

Kennedy, M. M. (2006). Knowledge and visión in teaching. Journal of Teacher Education, 57(3), 205-211. https://doi.org/10.1177/0022487105285639

Lefstein, A., \& Snell, J. (2011). Professional vision and the politics of teacher learning. Teaching and Teacher Education, 27, 505-514. https://doi.org/10.1016/j.tate.2010.10.004

Legge, M., \& Smith, W. (2014). Teacher education and experiential learning: A visual ethnography. Australian Journal of Teacher Education, 39(12), 94-109. https://doi.org/10.14221/ ajte.2014v39n12.7

Lindqvist, H., Weurlander, M., Wernerson, A., \& Thornberg, R. (2017). Resolving feelings of professional inadequacy: Student teachers' coping with distressful situations. Teaching and Teacher Education, 64, 270-279. https://doi.org/10.1016/j.tate.2017.02.019

Mannay, D. (2017). Métodos visuales, narrativos y creativos en investigación cualitativa. Madrid: Narcea.

Miller, K. (2016). Learning about children's school preparation through photographs: The use of photo elicitation interviews with low-income families. Journal of Early Childhood Research, 14(3), 261-279. https://doi.org/10.1177/1476718X14555703

Nghia, T. H. (2017). What hinders teachers from translating their beliefs into teaching behaviors: The case of teaching generic skills in Vietnamese universities. Teaching and Teacher Education, 64, 105-114. https://doi.org/10.1016/j.tate.2017.02.003

Parsons, S. A., Vaughn, M., Malloy, J. A., \& Pierczynski, M. (2017). The development of teachers' visions from preservice into their first years teaching: A longitudinal study. Teaching and 
Teacher Education, 64, 12-25. https://doi.org/10.1016/j.tate.2017.01.018

Popp, J. S., \& Goldman, S. R. (2016). Knowledge building in teacher professional learning communities: Focus of meeting matters. Teaching and Teacher Education, 59, 347-359. https://doi.org/10.1016/j.tate.2016.06.007

Rapley, T. (2014). Los análisis de la conversación, del discurso y de documentos. Madrid: Morata.

Richard, V. M., \& Lahman, M. K. E. (2015). Photo-elicitation: Reflexivity on method, analysis, and graphic portraits. International Journal of Research \& Method in Education, 38(1), 3-22. https://doi.org/10.1080/1743727X.2013.843073

Rose, G. (2016). Visual methodologies. An introduction to the interpretation of visual materials. London: SAGE.

Ruto-Korir, R., \& Beer, C. L.-D. (2012). The potential for using visual elicitation in understanding preschool teachers' beliefs of appropriate educational practices. South African Journal of Education, 32(4), 393-405. https://doi.org/10.15700/saje.v32n4a661

Schreier, M. (2014). Qualitative content analysis. In U. Flick (Ed.), The SAGE Handbook of Qualitative Data Analysis (pp. 49-63). London: SAGE.

Stake, R. E. (1998). Investigación con estudio de casos. Madrid: Morata.

Strickland, M. J., Keat, J. B., \& Marinak, B. A. (2010). Connecting worlds: Using photo narrations to connect immigrant children, preschool teachers, and immigrant families. School Community Journal, 20(1), 81-102.

Terry, L. (2007). Ethics and Contemporary Challenges in Health and Social Care. In A. Leathard \& S. McLaren (Eds.), Ethics. Contemporary Challenges in Health and Social Care (pp. 19-33). Great Britain: MPG Books Ltd. Bodmin. https://doi.org/10.1332/policypress/9781861347558 .003 .0002

Torre, D., \& Murphy, J. (2015). A diferent lens: Changing perspectives using photo-eliciation interviews. Education Policy Analysis Archives, 23, 1-26. https://doi.org/10.14507/epaa.v23.2051

Vaughn, M., Parsons, S. A., Keyes, C., Puzio, K., \& Allen, M. (2017). A multiple case study of teachers' visions and reflective practice. Reflective Practices, 18(4), 526-539. https://doi.org/ $10.1080 / 14623943.2017 .1323731$

Walls, J., \& Holquist, S. E. (2019). Through their eyes, in their words: using photo-elicitation to amplify student voice in policy and school improvement research. In S. K. \& L. L. (Eds.), Research Methods for Social Justice and Equity in Education (pp. 151-161). Cham, Germany: Palgrave Macmillan. https://doi.org/10.1007/978-3-030-05900-2_13

Walter, K. O., Baller, S. L., \& Kuntz, A. M. (2012). Two approaches for using web sharing and photography assignments to increase critical thinking in the health sciences. International Journal of Teaching and Learning in Higher Education, 24(3), 383-394. 